\title{
IMC-PID Controller and the Tuning Method in Pneumatic Control Valve Positioner
}

\author{
Yang Liu, Qunli Shang*, Shanen Yu, Yayao Fang, Zheng Ding and Jiajiang Li \\ College of Information Engineering Zhejiang University of Technology, Hangzhou, 310014, China
}

\begin{abstract}
Pneumatic control valve is the most common automatic instrument in process industry. The control performance of pneumatic control valve not only depends on the parameters of the controller, but also closely relates to the characteristics of the pneumatic control valve. This paper gives out a new method for parameter identification model based on the step response of the control valve system is given, and based on the model parameters this paper gives the calculation method of IMC-PID controller of pneumatic control valve, which proved by simulation and experiments to have fast, accurate and stable control performance.
\end{abstract}

Keywords: Pneumatic control valve, PID-tuning, ISE index, Internal model control.

\section{INTRODUCTION}

In process industry the control performance of the control loop affected by the parameters of the controller and the characteristic of the controlled object. Because of the remarkable effectiveness, simplicity of implementation broad applicability of the PID controller we mostly use PID control in the smart electronic-pneumatic valve positioner. However the parameters of PID controller which have good control performance is difficult to obtain.

This paper studies on pneumatic control algorithm of control valve. A new method for parameter identification model based on the step response of the control valve system is given and based on the model parameters this paper gives the calculation method of IMC-PID controller of pneumatic control valve, which proved to have fast, accurate and stable control performance.

There are many PID parameters tuning method nowadays, one of the most common is Zigeler-Nichols critical proportioning method, where the system is forced to maintain a constant-amplitude oscillation, and the parameters at critical oscillations can be used to design the PID controller. This method bases on the close loop data and experience. The IMC-PID method base on the model of the controlled object and the open loop data, which is more easily to obtain on-line. So the internal model PID setting method has better application prospect.

The pneumatic control valve can be seen as an aggregate of first order model whose parameters can be identified through its step response on different operating point and amplitude. By the tuning method of IMC-PID introduced in this paper, we can get the parameters of controller. Results of the experiments prove that IMC-PID in the control valve have good robustness and control performance.

\section{PARAMENTS IDENTIFICATION OF FIRST OR- DER TIME DELAY MODEL}

As most of the components in automatic industry, pneumatic control valve can be seen as a first order process model. The transfer function of the model is the following formula.

$$
G_{p}(\mathrm{~s})=\frac{K e^{-\tau s}}{T s+1}
$$

The unit step-respond of the process is

$$
\mathrm{y}(\mathrm{t})=\mathrm{K}\left(1-e^{-\frac{t-\tau}{T}}\right)+y(0)(t>\tau)
$$

Let

$$
\begin{aligned}
& \tilde{y}=c_{1} t+c_{0}=\ln \left(1-\frac{y(t)-y(0)}{K}\right) \\
& c_{1}=-\frac{1}{T}, c_{0}=\frac{\tau}{T}
\end{aligned}
$$

According to the formula of Least Squares Method, $c_{1}$ and $c_{0}$ can be calculate by the formula below.

$\left\{\begin{array}{c}c_{1}=\frac{\frac{1}{N} \sum_{n=1}^{N} \tilde{y}(n) n-\frac{1}{N^{2}} \sum_{n=1}^{N} \tilde{y}(n) \sum_{n=1}^{N} n}{\frac{1}{N} \sum_{n=1}^{N} n^{2}-\frac{1}{N^{2}}\left(\sum_{n=1}^{N} \tilde{y}(n)\right)^{2}} \\ c_{0}=\frac{1}{N} \sum_{n=1}^{N} \tilde{y}(n)-\frac{c_{1}}{N} \sum_{n=1}^{N} n\end{array}\right.$

So the parameters of the process model is

$$
\left\{\begin{array}{l}
T=-\frac{1}{c_{1}} \\
\tau=-\frac{c_{0}}{c_{1}} \\
K=\frac{y(\infty)}{r(t)}
\end{array}\right.
$$




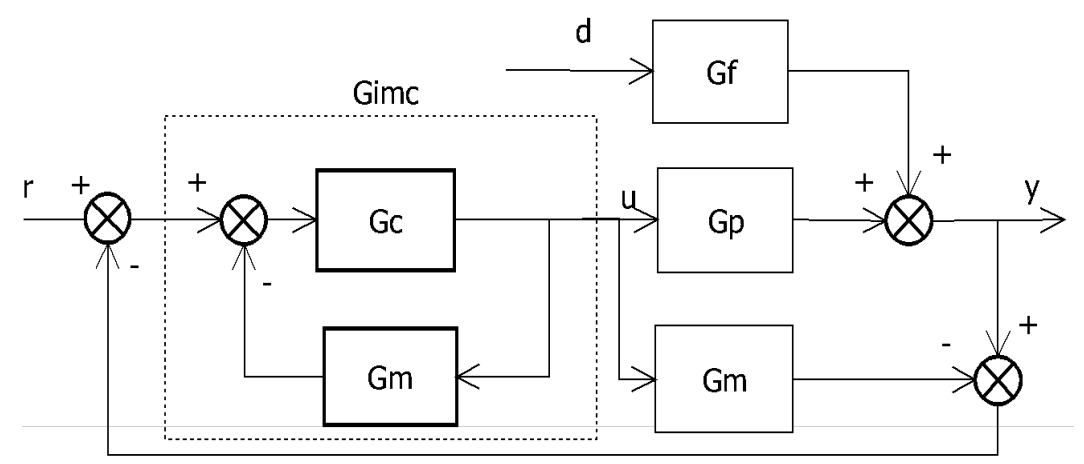

Fig. (1). The block diagram of the internal model controller and the feedback controller.

\section{DESIGN OF IMC-PID CONTROLLER}

Internal model control [1-5] is put forward by Garcia and Moriari in 1982. The design of the internal model controller base on a hypothetic process model and a low pass filter used to get robustness. The block diagram is as shown in Fig. (1).

In this figure, $G_{p}$ is the transfer function of the system, $G_{m}$ is the process model, $G_{I M C}$ is the internal model controller, $G_{c}$ is the feedback controller.

Factorize $G_{m}$ to $H_{0}$, which means the all-pass part of the system, and $H_{\text {min }}$, which means the minimum-phase part of the system. $H_{0}\left(e^{j \omega}\right)$ contains all the RHP zero point and time-delay part of the system. Usually $H_{0}$ can use the following formula to express, the superscript $\mathrm{H}$ means complex conjugate.

$$
\begin{gathered}
G_{m}=H_{0} H_{\text {min }} \\
H_{0}(s)=e^{-\theta s} \prod_{i} \frac{-s+\varepsilon_{i}}{s+\varepsilon_{i}^{H}} \\
R_{e}\left(\varepsilon_{i}\right), \theta>0
\end{gathered}
$$

Define the internal model controller as $G_{I M C}=H_{\min }^{-1} f . f$ is the low pass filter, and the formula is

$$
\mathrm{f}=1 /\left(1+\lambda s-e^{-\tau s}\right)
$$

So the relationship between the feedback controller $G_{c}$ and the internal model controller $G_{I M C}$ can be expressed by the formula below

$$
G_{c}=\frac{G_{I M C}}{1-G_{I M C} G_{m}}
$$

With formula 2-1 and 2-2, the expression of $G_{c}$ is the following formula

$G_{c}=\frac{H_{\min }^{-1} f}{1-e^{-\theta s} f \prod_{i}^{-\frac{-s+\varepsilon_{i}}{s+\varepsilon_{i}^{H}}}}$

As to a first order time delay process, the

$$
\begin{aligned}
H_{\min }(s) & =\frac{K}{T s+1} \\
H_{0}(s) & =e^{-\tau s}
\end{aligned}
$$

Use the formula (3) to get the formula below

$$
G_{c}=\frac{T s+1}{K\left(\lambda s+1-e^{-\tau s}\right)}
$$

The $e^{-\tau s}$ can be expressed by second order approximate

$$
e^{-\tau s}=\frac{1+\gamma_{1} \tau s+\gamma_{2} \tau^{2} s^{2}}{1+\delta \tau s}
$$

Then the controller of a first order time delay process is

$G_{C}=\frac{(T s+1)(1+\delta \tau s)}{K\left[\lambda+\left(\delta-\gamma_{1}\right) \tau+\left(\lambda \delta-\gamma_{2} \tau\right) \tau s\right] s}$

Usually, a PID controller has a construct like the formula following

$G_{C}(\mathrm{~s})=K_{C}\left(1+\frac{1}{T_{i} s}+\frac{T_{d} s}{T_{f} s+1}\right)$

The result of simultaneous of formula (4) and (5) is the parameters of the controller

$$
\left\{\begin{array}{c}
T_{f}=\frac{\left(\lambda \delta-\gamma_{2} \tau\right) \tau}{\lambda+\left(\delta-\gamma_{1}\right) \tau} \\
K_{c}=\frac{T+\delta \tau-T_{f}}{K\left[\lambda+\left(\delta-\gamma_{1}\right) \tau\right]} \\
T_{i}=K\left[\lambda+\left(\delta-\gamma_{1}\right) \tau\right] \\
T_{d}=\frac{T \delta \tau}{T+\delta \tau}-T_{f}
\end{array}\right.
$$

\section{THE EXPERIMENTAL PLATFORM}

Hardware: Process control computer, YAMATAKE smart valve positioner AVP-301, Control board, a pneumatic control valve of Zhejiang SANFANG party Co., Ltd. (sm:1170). The experimental platform is as follows.

Built the controller module by Matlab/Simulink platform in the computer. Send the given valve location SP by the serial port from the computer to the control valve positioner. The control board in the positioner transform the given valve location SP to current signal CVI and send it to I/P transfer, which can control the pressure Ps in the diaphragm chamber. The valve location feedback measure the valve location $\mathrm{x}$ as a voltage signal $u$. The control board transform $u$ to percentage number $\mathrm{x} \%$ and feed it back to the computer. With this experimental platform, we can do the open loop test and close loop experiment easily, and we can keep watch on the 


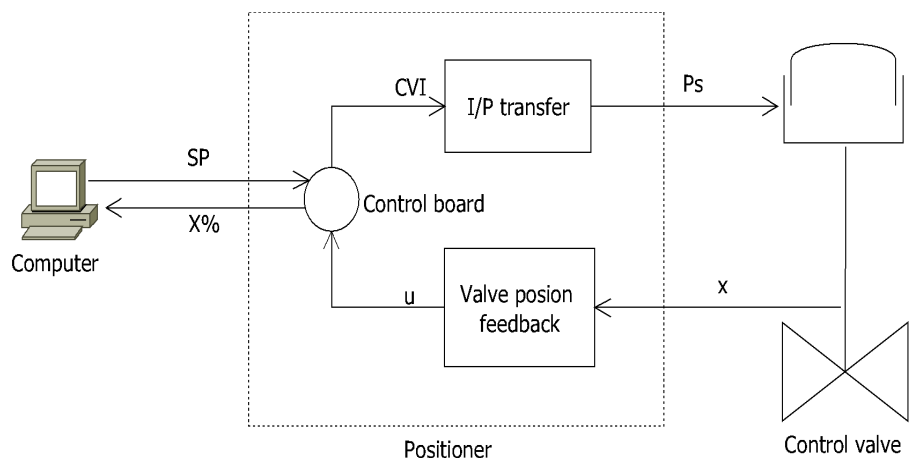

Fig. (2). The schematic diagram of the experimental platform.

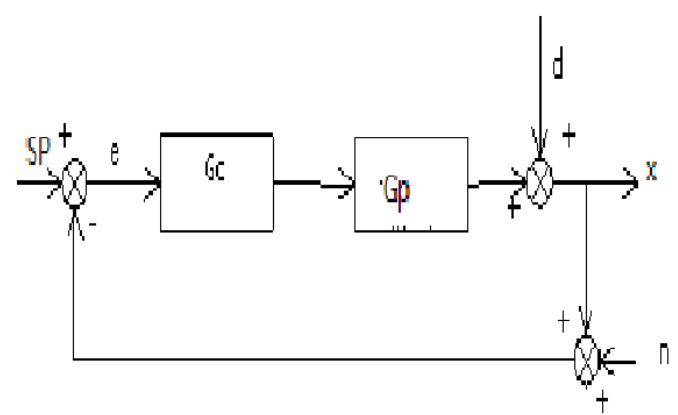

Fig. (3). The block diagram of the experimental platform.

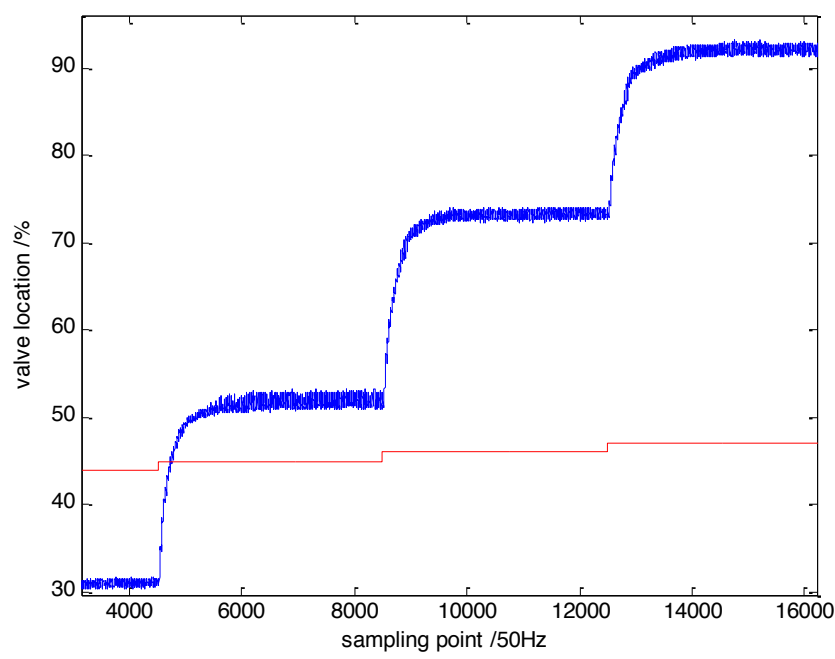

Fig. (4). The respond of the same amplitude forward step at different valve location.

valve location and save all the data needed. The block diagram of the platform. Fig. (3). shows the block diagram of the experimental platform.

\section{OPENLOOP TESTING AND PARAMENTS IDEN- TIFICATION}

All the data is normalization in this section. Use the computer send the given SP to the valve positioner through the serial port. Record the valve location data $\mathrm{x} \%$. The sampling and transmitting frequency is $50 \mathrm{~Hz}$.

\subsection{The Same Amplitude Forward Step at Different Valve Location}

Send the given SP as $44 \%$, waiting for the steady-state of the control valve. Then increase SP one by one until $47 \%$, every step last $100 \mathrm{~s}$. Record the valve location feedback signal $x \%$. The respond is as shown in the Fig. (4).

\subsection{Forward Step with Different Amplitude}

Send the given SP as $42 \%$, waiting for the steady-state of the control valve. Then increase SP to $44 \%$. The step last 


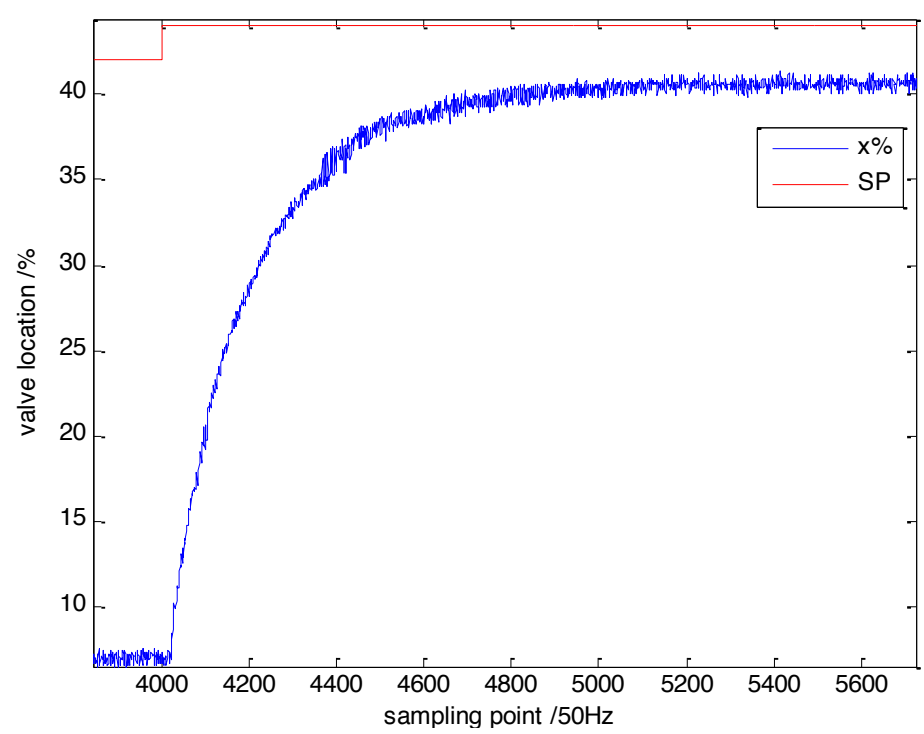

Fig. (5). The respond of forward step with different amplitude.

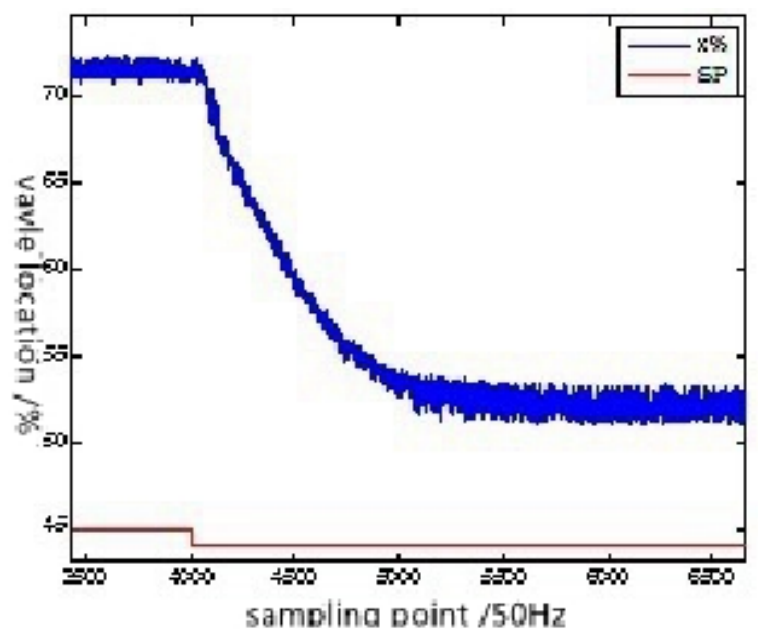

Fig. (6). Small amplitude backward step.

100 s. Record the valve location feedback signal $\mathrm{x} \%$. The respond is as shown in the Fig. (5).

\subsection{Backward Step Respond}

Send the given SP as $45 \%$, waiting for the steady-state of the control valve. Then reduce SP to $44 \%$. The step last $100 \mathrm{~s}$. Record the valve location feedback signal $\mathrm{x} \%$. The respond is as shown in the Fig. (6).

Send the given SP as $45 \%$, waiting for the steady-state of the control valve. Then reduce SP to $42 \%$. The step last 100 s. Record the valve location feedback signal $x \%$. The respond is as shown in the Fig. (7).

\subsection{Model Parameters Identification}

With the data of section 5.1 and 5.2, calculate the parameters of the process model. These parameters are given in Table 1.
The respond of small amplitude backward step is consistent with the forward step, while the big amplitude backward step have greater difference with the forward step. The respond of the big amplitude backward step has integral character, which would not be considered in the parameter tuning of the IMC-PID controller in the first. The average value of each parameter is $\mathrm{K}=20.1, \mathrm{~T}=4.1 \mathrm{~s}, \tau=0.5 \mathrm{~s}$. The simulation and verification is as shown in Fig. (8).

As the figure shows that these parameters can help to reappear the characters of the pneumatic control valve.

\section{IMC-PID CONTROLLER PARAMENTS TUNING}

According to the design of IMC-PID controller, $\lambda$ is the only adjustable parameters, which has a great relationship with control performance and robustness. The control performance can be evaluated by the ISE index, whose definition is the formula following 


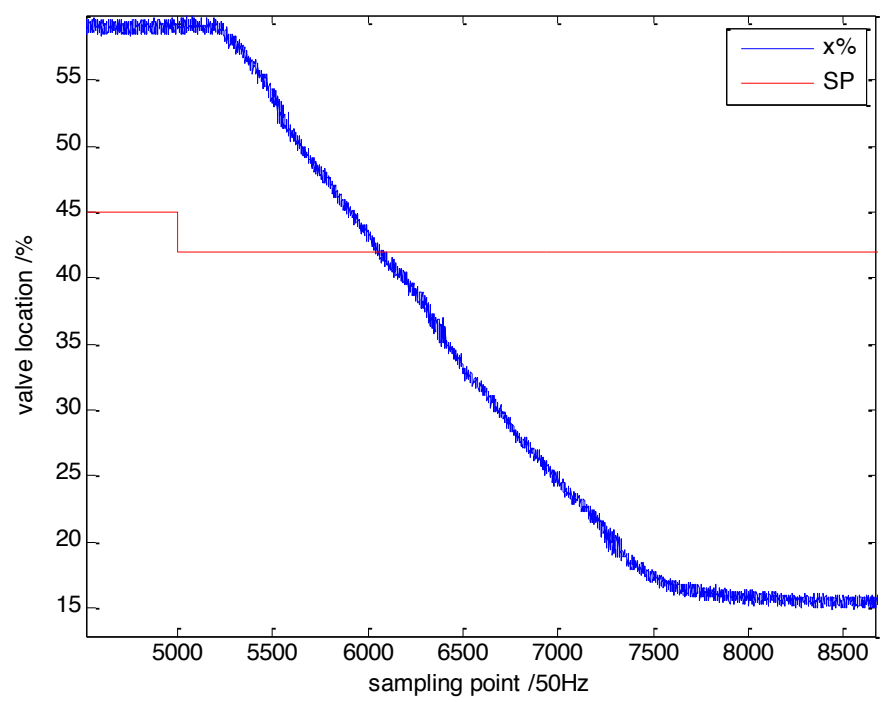

Fig. (7). Big amplitude backward step.

Table 1. Process parameters.

\begin{tabular}{|c|c|c|c|c|}
\hline SP (\%) & $\mathbf{4 4 \sim 4 5}$ & $\mathbf{4 5 \sim 4 6}$ & $\mathbf{4 6} \mathbf{4 7}$ & $\mathbf{4 2 \sim 4 4}$ \\
\hline \hline $\mathrm{K}$ & 20.5 & 20.7 & 49.8 & 17.5 \\
\hline $\mathrm{T}(/ \mathrm{s})$ & 4.0 & 3.8 & 0.2 & 3.6 \\
\hline $\boldsymbol{\tau}(/ \mathrm{s})$ & 0.4 & 0.6 & 0.6 & 0.5 \\
\hline
\end{tabular}

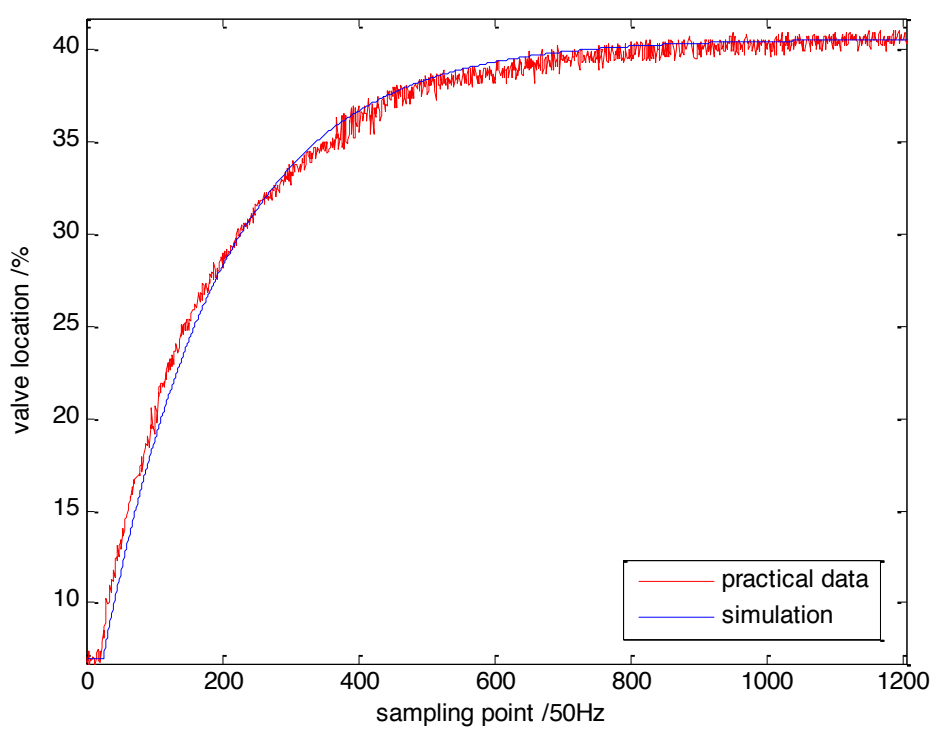

Fig. (8). Simulation and verification of the process model parameters.

$$
\mathrm{ISE}=\int\left(S P-x_{(t)}\right)^{2} d t
$$

Within the period the system reach the steady state, the ISE index is smaller, the performance of the control system is better. While the robustness of the system can be evaluated by $\mathrm{M}$ index.

$$
\mathrm{M}=\max (\tilde{\eta})
$$

$\tilde{\eta}$ is the complementary sensitivity function, which reflects the relationship between input SP and output x. And sensitivity function $\tilde{\varepsilon}$ reflects the relationship between disturbance $\mathrm{d}$ and system error e. 


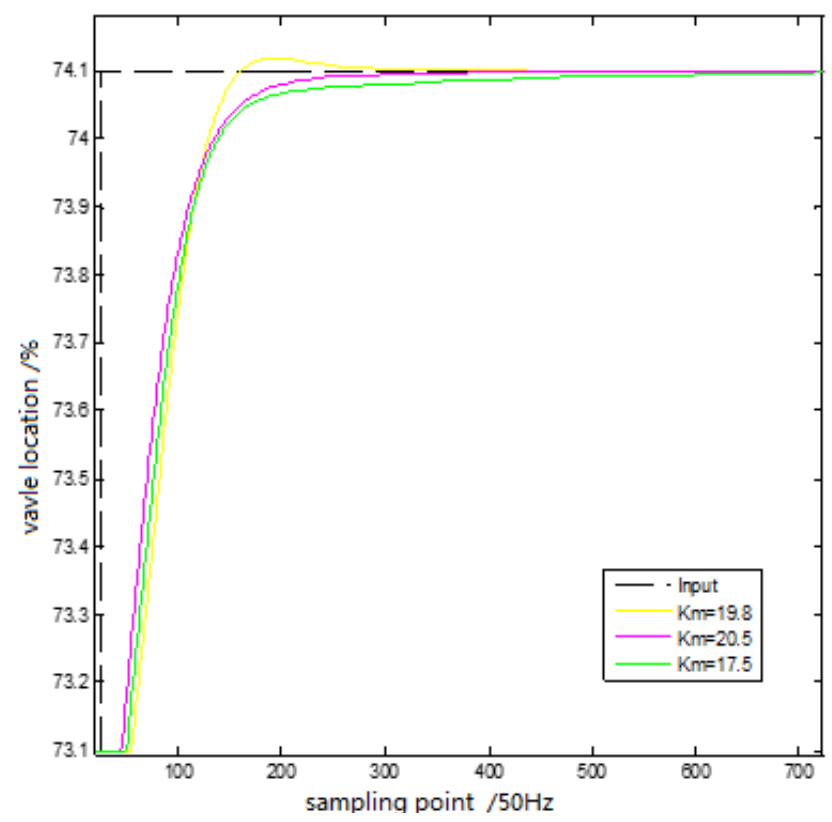

Fig. (9). IMC-PID close loop simulation.

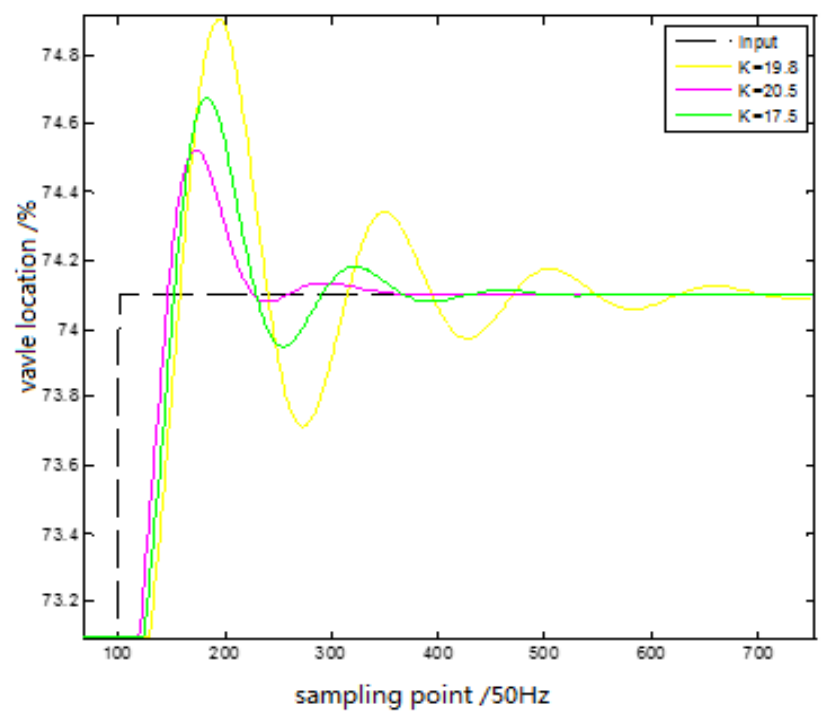

Fig. (10). Critical proportioning method simulation.

$$
\begin{aligned}
& \tilde{\varepsilon}=\frac{e}{d-S P}=\frac{1}{1+G_{P} G_{C}} \\
& \tilde{\eta}=\frac{x}{S P-n}=\frac{G_{P} G_{C}}{1+G_{P} G_{C}}
\end{aligned}
$$

Obviously $\tilde{\varepsilon}+\tilde{\eta}=1$. The occasion of $|\tilde{\varepsilon}|=0$ is not possible in the actual situation. In a certain frequency range we generally make $|\tilde{\varepsilon}|$ smaller is better. $|\tilde{\eta}|$ reflects the relationship between input SP and output y, and In a certain frequency range we generally make $|\tilde{\varepsilon}|$ close to 1 is better. According to the formula (3)

$$
\frac{x}{S P}=\frac{G_{P}(s) G_{c}(s)}{1+G_{P}(s) G_{C}(s)}
$$

$$
\begin{aligned}
\frac{x}{S P} & =\frac{(T s+1)\left(1+\gamma_{1} \tau s+\gamma_{2} \tau^{2} s^{2}\right)}{1+K\left[\lambda+\left(\delta-\gamma_{1}\right) \tau+\left(\lambda \delta-\gamma_{2} \tau\right) \tau s\right] s} \\
\tilde{\eta} & =\frac{(T s+1)\left(1+\gamma_{1} \tau s+\gamma_{2} \tau^{2} s^{2}\right)}{1+K\left[\lambda+\left(\delta-\gamma_{1}\right) \tau+\left(\lambda \delta-\gamma_{2} \tau\right) \tau s\right] s}
\end{aligned}
$$

Using the Marquardt optimization algorithm [6-10] to get the optimization parameter $\gamma_{1}=-0.614, \gamma_{2}=0.125, \delta=0$. Use different $\lambda / \tau$ to simulate to get the M index and ISE index. And $\lambda / \tau=0.4$ will get the right balance of both M and ISE. With the process model parameters $\mathrm{K}, \mathrm{T}, \tau$ in section 5.4 , we can calculate the IMC-PID controller parameters as $K_{C}=0.21, T_{i}=11.3, T_{d}=0.14, T_{f}=0.04$. 


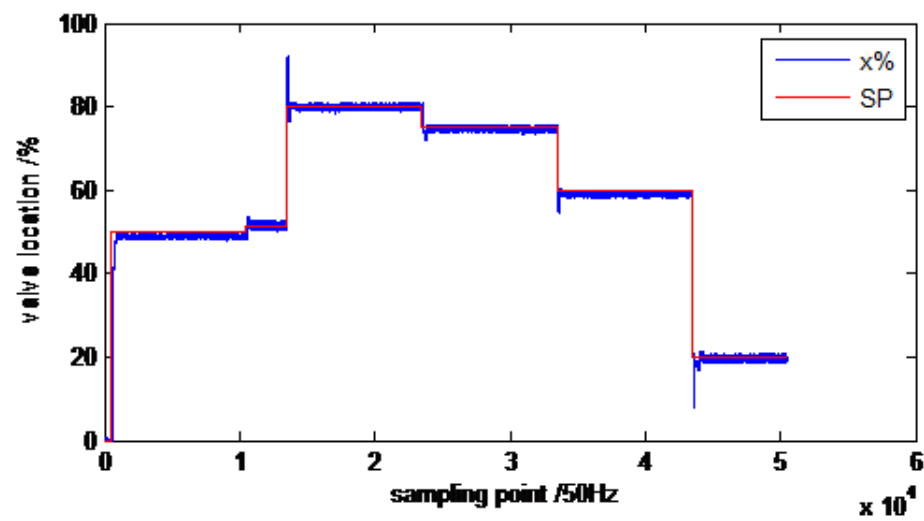

Fig. (11). Close loop experiment.
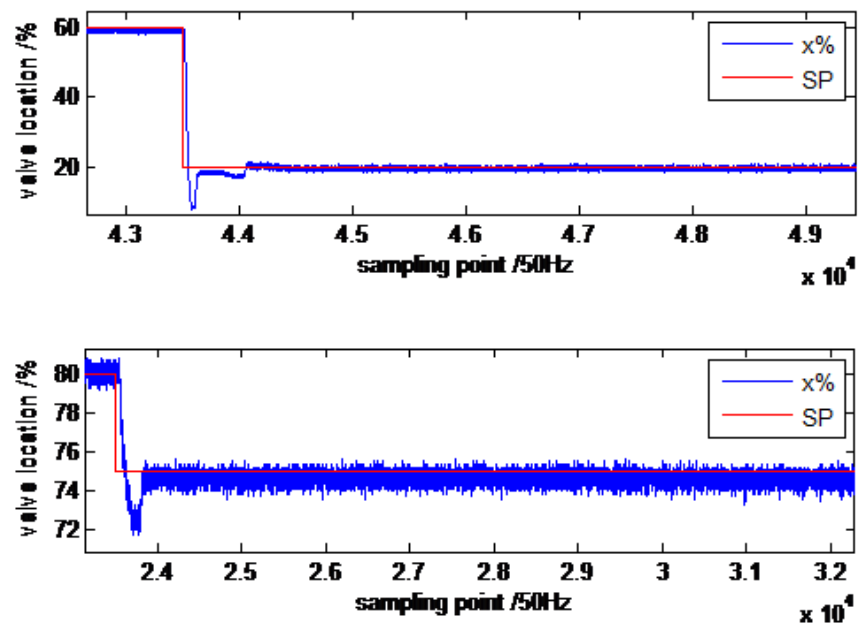

Fig. (12). Backward step performance in close loop experiment.

\section{CLOSE LOOP SIMULATION AND ANALYSIS}

This section talk about the difference between IMC-PID tuning method and critical proportioning method by simulation. At first use IMC-PID controller to do close loop simulation with the three process model. The figure bellow is the consequence of the simulation.

The ISE index of each process model is 53.88, 43.78 and 49.73 .

Then with the critical proportioning method we measure the system's critical proportion coefficient $\mathrm{K}_{\text {crit }}=0.6997$ and critical period of oscillation $T_{\text {crit }}=2 \mathrm{~s}$. According to the formula the controller parameters are $\mathrm{K}_{C}=0.31, \mathrm{~T}_{i}=1.72$, $T_{d}=0.06$. The Fig. (10) shows the consequence of the simulation.

The ISE index of each process model is 53.88, 43.78 and 49.73.

The difference of IMC-PID and the critical proportioning method is $-21.9,8.7,2.3$. The first one shows that IMC-PID is much better, while the others the critical proportioning method has a little advantage. However, IMC-PID has advantages on overshooting and the oscillation is less. Thou process model changed in three simulations, IMC-PID method get responds with a certain degree of coincidence, that means IMC-PID is more insensitive to the process model parameters and has better robustness.

\section{CLOSE LOOP EXPERIMENT AND ANALYSIS}

Setting the given valve location SP different amplitude and direction step to test the IMC-PID controller with close loop experiment. The consequence is as follows.

It is mentioned in section 5.3 that big amplitude backward step differs to the process model used to tuning the IMC-PID controller. There are some details about the backward step in close loop experiment in the two figures following. The detail is as shown in the Fig. (12).

All though the big backward step respond of the pneumatic control valve has great difference with the process model used to tuning the IMC-PID controller, the control performance is still good. 
Table 2. Comparison of time domain index.

\begin{tabular}{|c|c|c|c|}
\hline INDEX & $\mathbf{t}_{\mathrm{s}}$ & $\sigma$ & t \\
\hline \multirow{2}{*}{ IMC-PID } & 9.8 & 0.8 & 2.1 \\
\hline & 6.6 & 3 & 1.5 \\
\hline \multirow{4}{*}{ AVP101 } & 8.6 & 6 & 1.8 \\
\hline & 7.3 & 11 & 1.6 \\
\hline & 6.3 & 8.3 & 1.6 \\
\hline & 7.2 & 9.7 & 1.9 \\
\hline
\end{tabular}

The control valve can be seen as a switching system. It will overshoot at the first time of backward step in close loop control, then the control valve action is equivalent to the forward movement, so the forward process model will take effect, and IMC-PID can get a good control performance in the backward steps.

Statistics of the rise time $\mathrm{t}(/ \mathrm{s})$, overshooting $\sigma(\%)$, to reach to steady state time $t_{s}(/ \mathrm{s})$ of IMC-PID and compared with the Similar products in Japan YAMATAKE smart valve positioner AVP-101.

Both the index is as shown in the Table 2.

The comparison shows that IMC-PID tuning method reach the international standard in dynamic performance. And the inhibition of overshooting is notable.

\section{CONCLUSION}

The simulation and experiment proved that IMC-PID controller has better robustness and dynamic performance then the other tuning methods commonly used. The IMCPID tuning method given in this paper has the advantages of simple structure, convenient tuning parameter calculation, and the data is easy to get, which is Very suitable for industrial production process automation.

\section{CONFLICT OF INTEREST}

Conflict of interest statement: We declare that we have no conflict of interest.

\section{ACKNOWLEGEMENTS}

The paper supported by National Natural Science Foundation of China, No. 61174108 .

\section{REFERENCES}

[1] Garcia C. E., Morari M., Internal Model Control. 1. A Unifying Review and Some New Results, Ind Eng Chem Process Des Dev, 21, 2, 1982, pp. 308.

[2] Marquardt D. W., An algorithm for least squares estimation of nonlinear parameters, J Soc Ind App Math, 11, 2, 1963, pp. 329-336.

[3] Hang C. C., K. J. A. Strom, W. K. Ho, Refinements of the ZieglerNichols Tuning formula, IEE Proc-D, 38, 2, 1991, pp. 111-118.

[4] A Strom K. J., Hagglund T., Automatic tuning of simple regulators with specifications on phase and amplitude margins Automatic, Automatica, 20, 1984, pp. 645-6514.

[5] Riveara D. E., Morari M., Skogested S., Internal Model Control. 4. PID Controller Design, Ind Eng Chem Process Des Dev, 25, 1, 1986, pp. 252-265.

[6] Moriai M. Zafiriou, Robust Process Control. Prentice Hall, Eaglewood Cliffs, N. J., 1989.

[7] Zhang, S.W.,Lan, T.X.,Fang, X.F. Application of grey correlation analysis on tool selection[J].Advanced Materials Research,Vol.97101,2010,pp:2485-2488.

[8] Nahas E. P., Henson M. A., Seborg D. E., Nonlinear Internal Model Control Strategy for Neural Network Models, Computers Chem. Eng, 16, 12, 1992, pp. 1039-1057.

[9] Laughlin D. L., Jordan K. G., Morari M., Internal Control and Process Uncertainty: Mapping Uncertainty Regions for SISO Controller Design, Inj. J. Control, 44, 6, 1986, pp. 1675-1698.

[10] Chien I. L., P. S. Fruehanf, Consider IMC tuning to improve controller performance, Chem Eng Prog, 86, 1990, pp. 33-44.

(C) Liu et al.; Licensee Bentham Open.

This is an open access article licensed under the terms of the Creative Commons Attribution Non-Commercial License (http://creativecommons.org/licenses/by-nc/3.0/) which permits unrestricted, non-commercial use, distribution and reproduction in any medium, provided the work is properly cited. 